\title{
Serum exosomal miR-328, miR-575, miR-134 and miR-671-5p as potential biomarkers for the diagnosis of Kawasaki disease and the prediction of therapeutic outcomes of intravenous immunoglobulin therapy
}

\author{
XIAOFEI ZHANG ${ }^{1}$, GUANGDA XIN ${ }^{2}$ and DAJUN SUN ${ }^{3}$ \\ Departments of ${ }^{1}$ Pediatrics, ${ }^{2}$ Nephrology and ${ }^{3}$ Vascular Surgery, China-Japan Union \\ Hospital of Jilin University, Changchun, Jilin 130033, P.R. China
}

Received November 30, 2017; Accepted May 17, 2018

DOI: $10.3892 /$ etm.2018.6458

\begin{abstract}
The present study was conducted to screen serum exosomal microRNAs (miRNAs) for the early diagnosis of Kawasaki disease (KD) and to investigate their underlying mechanisms by analyzing microarray data under accession numbers GSE60965 [exosomal miRNA, including three pooled serum samples from 5 healthy children, 5 patients with $\mathrm{KD}$ and 5 patients with KD following intravenous immunoglobulin (IVIG) therapy] and GSE73577 (mRNA, including peripheral blood mononuclear cell samples from 19 patients with KD prior to and following IVIG treatment) from the Gene Expression Omnibus database. Differentially expressed miRNAs (DE-miRNAs) and genes (DEGs) were identified using the Linear Models for Microarray data method, and the mRNA targets of DE-miRNAs were predicted using the miRWalk 2.0 database. The functions of the target genes were analyzed using the Database for Annotation, Visualization and Integrated Discovery (DAVID). As a result, 65 DE-miRNAs were identified with different expression patterns between the healthy children and patients with KD and between patients with KD and patients with KD following IVIG therapy. The target genes of 15 common DE-miRNAs were predicted. Following overlapping the target genes of DE-miRNAs with 355 DEGs, 28 common genes were identified and further screened to construct a network containing 30 miRNA-mRNA regulatory associations. Of these associations, only miR-328-spectrin $\alpha$, erythrocytic 1 , miR-575-cyclic AMP-responsive element-binding protein 5/b-1,4-galactosyltransferase 5/WD repeat and FYVE domain-containing $3 /$ cystatin-A/C-X-C motif chemokine receptor $1 /$ protein
\end{abstract}

Correspondence to: Dr Dajun Sun, Department of Vascular Surgery, China-Japan Union Hospital of Jilin University, 126 Xiantai Street, Changchun, Jilin 130033, P.R. China

E-mail: djvaso@163.com

Key words: Kawasaki disease, vasculitis, biomarker, exosome, microRNA, inflammatory, intravenous immunoglobulin phosphatase 1 regulatory subunit 3B, miR-134-acyl-CoA synthetase long chain family member 1/C-type lectin domain family 1 member A and miR-671-5p-tripartite motif containing 25/leucine rich repeat kinase $2 /$ kinesin family member $1 \mathrm{~B} /$ leucine rich repeat neuronal 1 were involved in the negative regulation of gene expression. Functional analysis indicated that the identified target genes may be associated with inflammation. Accordingly, serum exosomal miR-328, miR-575, miR-134 and miR-671-5p may act as potential biomarkers for the diagnosis of KD and the prediction of outcomes of the IVIG therapy by influencing the expression of inflammatory genes.

\section{Introduction}

Kawasaki disease (KD) is a common, acute, systemic vasculitis that occurs in children $<5$ years old in Asian populations, with estimated incidence rates of 264.8, 134.4, 66.24 and 71.9 per 100,000 children in Japanese (1), Korean (2), Taiwanese (3) and Chinese (4) populations, respectively. KD predominantly affects small- to medium-sized vessels, including coronary arteries (5). If diagnosis is delayed and KD is left untreated, coronary artery lesions may develop in $25 \%$ of patients, which, in turn, increases the formation risk of coronary artery aneurysms (CAAs) and, subsequently, can induce coronary artery thrombosis, myocardial infarction or even sudden death $(6,7)$. Intravenous immunoglobulin (IVIG) infusion is an effective, first-line therapy for KD (8). However, $30 \%$ of cases have been reported to be unresponsive to IVIG, and additional therapy is required (9). If patients who are unresponsive to IVIG therapy are not identified in a timely manner, CAAs may still develop (10). Therefore, the early diagnosis of KD and the prediction of the therapeutic outcomes of IVIG are important issues.

At present, the diagnosis and evaluation of therapeutic effects primarily depend on clinical symptoms (including fever for $\geq$ five days, conjunctivitis, erythema of the lips and oral mucosa, extremity swelling, rash and cervical lymphadenopathy) (11), and ultrasonic imaging results (including QT interval dispersion) (12). However, these presentations overlap with other febrile illnesses in childhood (including 
epistaxis, scarlet fever, bovillae or juvenile idiopathic arthritis) and, therefore, are not specific (13). In addition, accumulating evidence indicates that the development of KD may be associated with the abnormal activation of the immune system and inflammation $(14,15)$. Several inflammatory cytokines in the serum [including tumor necrosis factor $\alpha(\mathrm{TNF}-\alpha)$, interleukin (IL)-6, IL-17, IL-22 and IL-23] have been suggested to be biomarkers for the diagnosis of KD and IVIG therapy (16-18). However, certain studies reported that inflammatory markers are also non-specific and usually decreased in patients who are unresponsive to initial therapy $(19,20)$. Therefore, novel biomarkers for the diagnosis of KD and for the prediction of therapeutic effects are required.

MicroRNAs (miRNAs) are endogenous, small, non-coding RNAs ( $\sim 19-22$ nucleotides in length) that serve roles in the regulation of diverse physiological and pathological processes through the complementary binding of target genes in the 3'untranslated region, for cleavage or translational repression (21). Furthermore, miRNAs can be present in the serum due to resistance against ribonuclease digestion and serum miRNAs are stable with consistent levels among individuals of the same species (21). Therefore, serum miRNAs that regulate the expression of inflammatory genes may serve as potential biomarkers for the diagnosis of KD and the prediction of therapeutic outcomes. This hypothesis has been supported by recent studies. Using miRNA microarray assays, Yun et al (22) demonstrated that miR-200c and miR-371-5p were significantly upregulated in children with KD, compared with controls. Further, Zhang et al (23) observed that serum miR-200c and miR-371-5p levels were significantly increased in patients with KD who were unresponsive to IVIG therapy compared with patients with KD who exhibited a good response to IVIG therapy. The combination of serum miR-200c and miR-371-5p exhibited high predictive values for the diagnosis of patients with KD [area under the curve $(\mathrm{AUC})=0.95]$ and for those with an excellent IVIG response (AUC=0.97) (23). Furthermore, Yun et al (22) predicted that miR-200c and miR-371 may be involved in KD by targeting the regulation of a series of inflammatory response genes. In addition to their intracellular presence, miRNAs can also be enveloped into nanoparticles, termed exosomes, which maintain the integrity of miRNAs and transfer the miRNAs to recipient cells, influencing their phenotypes (24). Therefore, serum exosomal miRNAs may represent important biomarkers for various diseases (24). To date, exosomal miRNAs have been demonstrated to be useful in the early diagnosis of several cancers $(25,26)$. The studies on KD and the IVIG therapy remain rare, except for the study by Jia et al (27), which identified four exosomal miRNA biomarkers, including miR-1246, miR-4436b-5p, miR-197-3p and miR-671-5p. The roles and mechanisms through which these miRNAs may act were not investigated.

Several studies reported that the addition of serum induces the production of pro-inflammatory cytokines (IL-1Ra, IFN $\alpha$, IL-6, TNF- $\alpha$ and C-C motif chemokine 20) by peripheral blood mononuclear cells (PBMCs) (28-31), indicating that serum-secreted factors (including exosomes) may be of importance in maintaining this function. This hypothesis was indirectly demonstrated by the following studies. Harshyne et al (32) demonstrated that exosome-enriched fractions from sera of patients with glioblastoma are capable of inducing scavenger receptor cysteine-rich type 1 protein M130 expression in normal monocytes. Zhou et al (33) demonstrated that serum exosomes primed macrophage polarization towards the M2 phenotype. Accordingly, the present study hypothesized that serum exosomal miRNAs may be involved in KD by influencing the genes expressed by PBMCs.

The aim of the present study was to further analyze the exosomal miRNA microarray data established by Jia et al (27) and to predict their functions by overlapping their predicted target genes with differentially expressed genes (DEGs) in PBMCs (34). Compared with the study by Jia et al (27), the cut-off value [ $\log$ fold change $(\mathrm{FC}) \geq 6$ vs. FC $>200$ ] for screening differentially expressed miRNAs (DE-miRNAs) was broadened to identify an increased number of exosomal miRNAs.

\section{Materials and methods}

Microarray data. The miRNA microarray data were collected from the Gene Expression Omnibus (GEO) database (www.ncbi.nlm.nih.gov/geo), under the accession number GSE60965, which included the exosomal miRNA profiles of three pooled serum samples collected from 5 healthy children [the normal (N) group], 5 patients with Kawasaki disease (the KD group) and 5 patients with KD following IVIG therapy (the IVIG group) (27). The microarray platform was GPL16730 Agilent-039659 hs_miR_18_addvirus 038169.

The mRNA microarray dataset was also available from the GEO database, under the accession number GSE73577, in which PBMCs samples of 19 patients with KD were investigated prior to and following IVIG treatment (34). This dataset was dependent on a two-channel microarray platform (GPL4133, Agilent-014850 Whole Human Genome Microarray 4x44K $\mathrm{G} 4112 \mathrm{~F})$, and two repeats were performed for each patient.

Data normalization and the identification of DE-miRNAs and $D E G s$. The raw data from the two datasets and the annotated symbols were downloaded from the corresponding platforms. All expression values were logarithmically transformed (base 2) and quantile normalized using the Bioconductor preprocessCore package (version 1.28.0; www.bioconductor. org/packages/release/bioc/html/preprocessCore.html) (35).

Since one pooled sample per group was used for the analysis of exosomal miRNA profiles, the DE-miRNAs between the $\mathrm{N}$ and $\mathrm{KD}$ groups and between the KD and IVIG groups were only screened by calculating the $\log F C$ value. $\mid \log F C l \geq 6$ was set as the threshold value. Further, a Venn diagram was built using the Bioinformatics and Evolutionary Genomics online tool (bioinformatics.psb.ugent.be/webtools/Venn) to determine the overlap between DE-miRNAs that were upregulated or downregulated in the KD group compared with the $\mathrm{N}$ group and DE-miRNAs that were downregulated or upregulated in the IVIG group compared with the KD group, so that the DE-miRNA alterations that were observed in the KD group and were reversed by IVIG could be identified.

The DEGs of patients with KD prior to and following IVIG treatment were identified using the Linear Models for Microarray data (LIMMA) package (v.2.16.4; bioconductor.org/packages/release/bioc/html/limma.html) (36) 

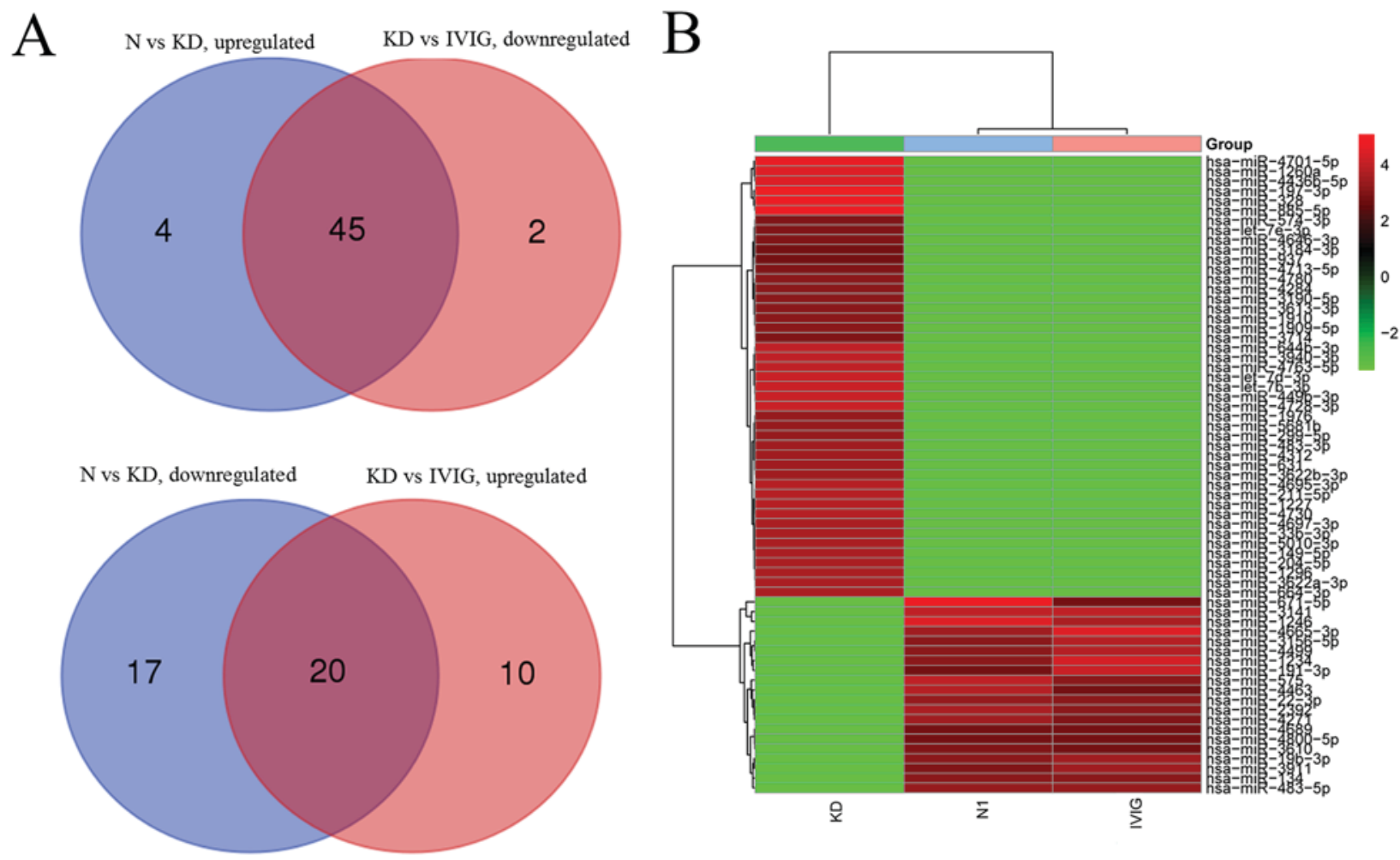

Figure 1. Differentially expressed serum exosomal miRNAs identified between healthy children and patients with KD, or between patients with KD and patients with KD following IVIG therapy. (A) Venn diagrams to analyze the common miRNAs between the two comparisons. (B) Heatmap indicating the differentially expressed miRNAs to distinguish between the three groups. KD, patients with Kawasaki disease; IVIG, intravenous immunoglobulin; miR, microRNA; N, negative control healthy children.

in the Bioconductor $\mathrm{R}$ software environment (v.3.4.1; http://www.R-project.org/). The P-values of the DEGs were calculated using Student's t-test. $\mathrm{P}<0.05$ and $\mid \log \mathrm{FCl}>0.5$ were considered the cut-off criteria.

A heat map of DE-miRNAs and DEGs was plotted using the pheatmap $\mathrm{R}$ package (v.1.0.8; cran.r-project. org/web/packages/pheatmap/index.html), based on a bidirectional hierarchical clustering analysis with Euclidean distance (37).

Target gene predictions for DE-miRNAs. mRNA targets of DE-miRNAs were predicted using the miRWalk database (v.2.0; zmf.umm.uni-heidelberg.de/apps/zmf/mirwalk2), which includes 12 prediction algorithms (DIANA-microTv4.0, DIANA-microT-CDS, miRanda-rel2010, mirBridge, miRDB4.0, miRmap, miRNAMap, PicTar2, PITA, RNA22v2, RNAhybrid2.1 and Targetscan6.2). Only the miRNA-target gene interactions predicted by $\geq$ four algorithms were collected to construct a regulatory network and visualized using Cytoscape software (v.2.8; www.cytoscape.org) (38).

In addition, the target genes of DE-miRNAs and DEGs were analyzed using a Venn diagram (bioinformatics.psb. ugent.be/webtools/Venn) to identify the overlapping genes. The shared DE-miRNA-target interactions were also visualized using Cytoscape software (v.2.8; www.cytoscape.org) (38).

Functional enrichment analysis. To analyze the potential functions of identified target genes, Gene Ontology (GO) and
Kyoto Encyclopedia of Genes and Genomes (KEGG) pathway enrichment analyses were performed using the Database for Annotation, Visualization and Integrated Discovery (DAVID) 6.8 online tool (david.abcc.ncifcrf.gov) (39). $\mathrm{P}<0.05$ was considered to indicate a statistically significant difference.

\section{Results}

Identification of exosomal DE-miRNAs. According to the threshold of $\mid \log \mathrm{FCl} \geq 6,86$ exosomal DE-miRNAs were identified between the $\mathrm{N}$ and KD groups, including 49 that were upregulated and 37 that were downregulated, while 77 DE-miRNAs were identified between the KD and IVIG groups, including 30 that were upregulated and 47 that were downregulated.

Following overlapping the DE-miRNAs that were upregulated in the KD group compared with the $\mathrm{N}$ group with the DE-miRNAs that were downregulated in the IVIG group compared with the KD group, 45 common DE-miRNAs were obtained. A total of 20 common DE-miRNAs were identified when the DE-miRNAs that were downregulated in the KD group compared with the $\mathrm{N}$ group were overlapped with the DE-miRNAs that were upregulated in the IVIG group compared with the KD group (Fig. 1A; Table I). These results suggested that these 65 shared DE-miRNAs may be biomarkers for the development of KD and could be reversed by IVIG. Therefore, they may also be used as biomarkers for evaluating the effectiveness of IVIG. These DE-miRNAs 
Table I. DE-miRNAs in serum exosomes from healthy children, patients with KD and patients with KD following IVIG therapy.

\begin{tabular}{|c|c|c|}
\hline miRNA & N vs. KD (logFC) & KD vs. IVIG $(\log F C)$ \\
\hline hsa-miR-4695-3p & 7.14 & -6.98 \\
\hline hsa-miR-328 & 8.23 & -8.07 \\
\hline hsa-miR-631 & 6.78 & -6.62 \\
\hline hsa-miR-3190-5p & 6.45 & -6.29 \\
\hline hsa-miR-574-3p & 6.30 & -6.15 \\
\hline hsa-miR-1260a & 7.85 & -7.69 \\
\hline hsa-miR-3622a-3p & 6.92 & -6.76 \\
\hline hsa-miR-197-3p & 8.40 & -8.24 \\
\hline hsa-miR-664-3p & 6.92 & -6.76 \\
\hline hsa-miR-3622b-3p & 6.75 & -6.60 \\
\hline hsa-miR-3613-3p & 6.46 & -6.30 \\
\hline hsa-miR-33b-3p & 7.05 & -6.89 \\
\hline hsa-miR-149-5p & 6.95 & -6.80 \\
\hline hsa-let-7d-3p & 7.41 & -7.25 \\
\hline hsa-miR-4780 & 6.50 & -6.34 \\
\hline hsa-miR-204-5p & 6.95 & -6.79 \\
\hline hsa-miR-3940-3p & 7.28 & -7.12 \\
\hline hsa-miR-1227 & 7.09 & -6.94 \\
\hline hsa-miR-937 & 6.20 & -6.04 \\
\hline hsa-miR-4763-5p & 7.30 & -7.15 \\
\hline hsa-miR-4713-5p & 6.22 & -6.06 \\
\hline hsa-let-7b-3p & 7.47 & -7.31 \\
\hline hsa-miR-211-5p & 7.15 & -6.99 \\
\hline hsa-miR-4730 & 7.12 & -6.96 \\
\hline hsa-miR-885-5p & 8.16 & -8.00 \\
\hline hsa-miR-3184-3p & 6.17 & -6.01 \\
\hline hsa-let-7e-3p & 6.25 & -6.10 \\
\hline hsa-miR-644b-3p & 7.33 & -7.18 \\
\hline hsa-miR-1909-5p & 6.39 & -6.23 \\
\hline hsa-miR-483-3p & 6.85 & -6.69 \\
\hline hsa-miR-4436b-5p & 7.77 & -7.61 \\
\hline hsa-miR-5681b & 6.72 & -6.56 \\
\hline hsa-miR-4646-3p & 6.27 & -6.11 \\
\hline hsa-miR-1910 & 6.40 & -6.24 \\
\hline hsa-miR-299-5p & 6.69 & -6.54 \\
\hline hsa-miR-4312 & 6.83 & -6.68 \\
\hline hsa-miR-449b-3p & 7.45 & -7.29 \\
\hline hsa-miR-4701-5p & 7.97 & -7.82 \\
\hline hsa-miR-1296 & 6.91 & -6.75 \\
\hline hsa-miR-4728-3p & 7.45 & -7.29 \\
\hline hsa-miR-4284 & 6.55 & -6.39 \\
\hline hsa-miR-1976 & 6.65 & -6.49 \\
\hline hsa-miR-4697-3p & 7.00 & -6.85 \\
\hline hsa-miR-3714 & 6.38 & -6.22 \\
\hline hsa-miR-5010-3p & 7.03 & -6.88 \\
\hline hsa-miR-3141 & -7.30 & 7.33 \\
\hline hsa-miR-134 & -6.45 & 6.40 \\
\hline hsa-miR-4800-5p & -6.19 & 6.10 \\
\hline hsa-miR-19b-3p & -6.50 & 6.79 \\
\hline hsa-miR-4665-3p & -6.72 & 7.79 \\
\hline
\end{tabular}

Table I. Continued.

\begin{tabular}{lcc}
\hline miRNA & N vs. KD $(\log F C)$ & KD vs. IVIG (logFC) \\
\hline hsa-miR-483-5p & -6.70 & 6.71 \\
hsa-miR-4463 & -7.07 & 6.13 \\
hsa-miR-1234 & -6.38 & 7.60 \\
hsa-miR-2392 & -6.91 & 6.38 \\
hsa-miR-22-3p & -6.71 & 6.44 \\
hsa-miR-4689 & -6.13 & 6.19 \\
hsa-miR-575 & -7.37 & 6.50 \\
hsa-miR-3911 & -6.30 & 6.75 \\
hsa-miR-191-3p & -6.06 & 7.44 \\
hsa-miR-1246 & -7.85 & 7.04 \\
hsa-miR-4271 & -6.83 & 6.26 \\
hsa-miR-671-5p & -8.16 & 6.14 \\
hsa-miR-3610 & -6.25 & 6.16 \\
hsa-miR-3156-5p & -6.40 & 7.17 \\
hsa-miR-4499 & -6.39 & 7.07 \\
\hline
\end{tabular}

These miRNAs were the shared differentially expressed miRNAs of the comparisons between $\mathrm{N}$ and KD, and between KD and IVIG. DE-miRNAs, differentially expressed miRNAs; $\mathrm{N}$, normal; KD, Kawasaki disease; IVIG, intravenous immunoglobulin; FC, fold change; miRNA or miR, microRNA.

could clearly distinguish between the three groups, and the $\mathrm{N}$ and IVIG groups were clustered identically (Fig. 1B).

Target genes for DE-miRNAs. To understand how these 65 exosomal miRNAs may influence the pathogenesis of KD, their target genes were predicted using the miRWalk 2.0 database. As a result, only 1,192 potential targets for the 15 DE-miRNAs were identified and no targets were predicted for the remaining 50 DE-miRNAs.

To indirectly demonstrate that the potential target genes of the identified DE-miRNAs were indeed differentially expressed in KD, and, since the present study hypothesized that exosomal DE-miRNAs in serum may serve roles in KD by regulating immune cells, the mRNA expression profiles from PBMCs of patients with KD prior to and following IVIG treatment were also investigated. As a result, 355 DEGs were screened, including 35 that were upregulated and 320 that were downregulated (Fig. 2A). Following overlapping these DEGs with the predicted target genes of the DE-miRNAs, 28 common DEGs were obtained (Fig. 2B; Table II), which constituted a network containing $30 \mathrm{miRNA}-\mathrm{mRNA}$ regulatory associations. Of these, only miR-328-spectrin $\alpha$, erythrocytic 1 (SPTA1), miR-575-cyclic AMP-responsive element-binding protein 5 (CREB5)/ $\beta$-1,4-galactosyltransferase 5 (B4GALT5)/WD repeat and FYVE domain-containing 3/cystatin-A/C-X-C motif chemokine receptor 1 (IL8RA)/protein phosphatase 1 regulatory subunit 3B (PPP1R3B), miR-134-acyl-CoA synthetase long chain family member 1 (ACSL1)/C-type lectin domain family 1 member A and miR-671-5p-tripartite motif containing 25/leucine rich repeat kinase 2 (LRRK2)/kinesin family member $1 \mathrm{~B} /$ leucine rich repeat neuronal 1 were involved the negative regulation of expression (Fig. 3). 


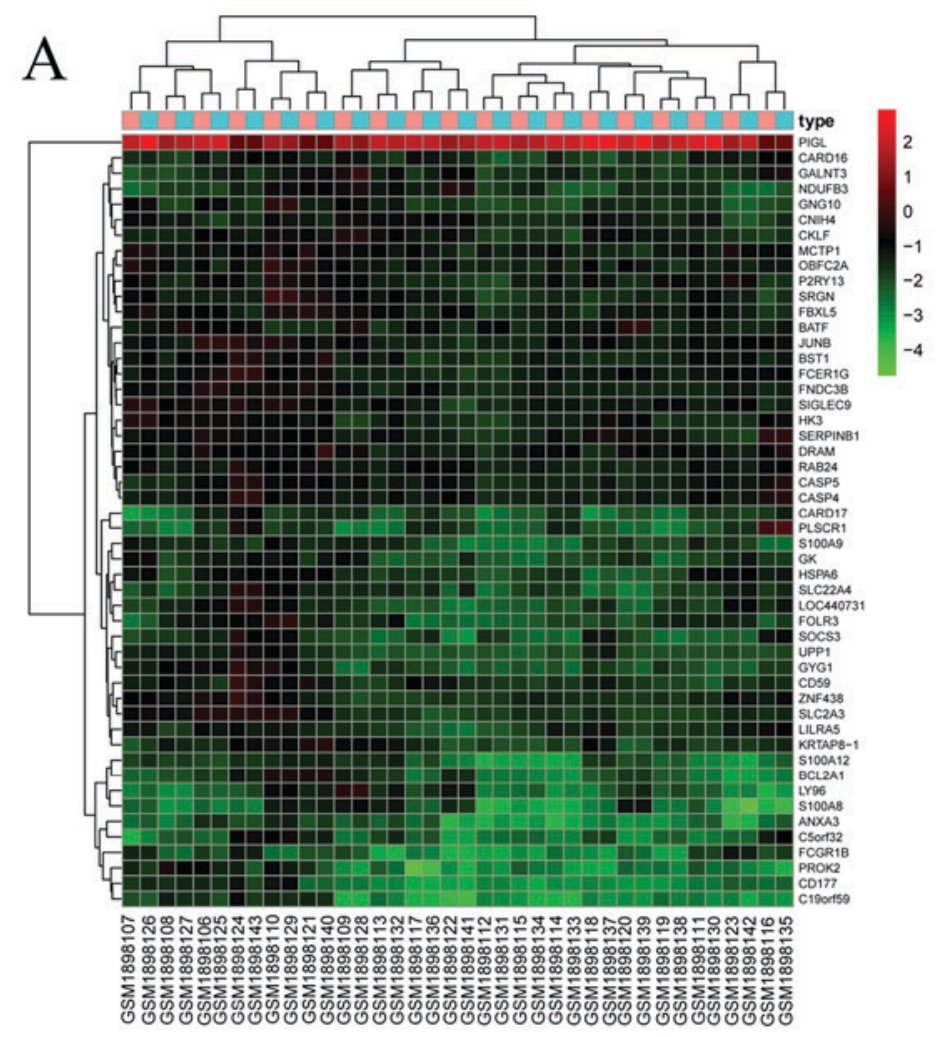

\section{B}

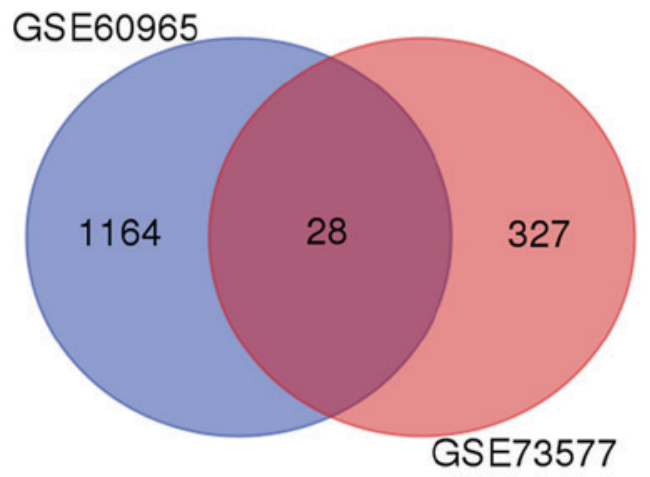

Figure 2. DEGs in peripheral blood mononuclear cells between patients with KD prior to and following IVIG therapy. (A) Heatmap indicating the differentially expressed genes to distinguish between the KD and IVIG groups. (B) Venn diagram to analyze the overlapping genes between the differentially expressed genes and the target genes of differentially expressed microRNAs. DEGs, differentially expressed genes; KD, Kawasaki disease; IVIG, intravenous immunoglobulin.

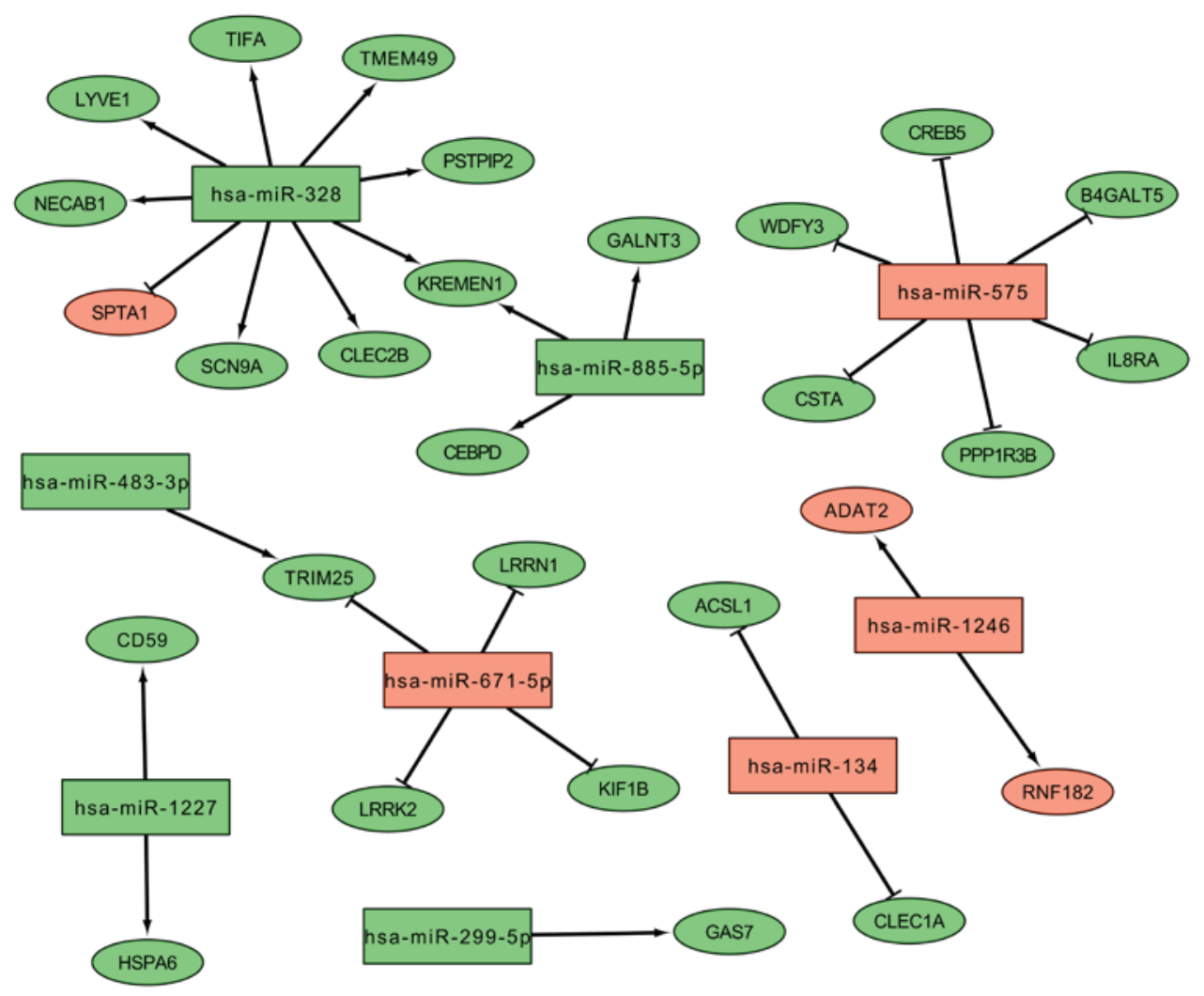

Figure 3. The regulatory associations between DE-miRNAs and DEGs. miR, microRNA; DE-miRNAs, differentially expressed miRNAs; DEGs, differentially expressed genes; red, upregulated; green, downregulated; arrowhead, similar expression trend between miRNAs and target genes; vertical line, opposite expression trend between miRNAs and target genes. 
Table II. DEGs in peripheral blood mononuclear cells from patients with KD prior to and following intravenous immunoglobulin therapy.

\begin{tabular}{|c|c|c|}
\hline Gene & Log fold change & P-value \\
\hline PIGL & 1.73 & $1.13 \times 10^{-18}$ \\
\hline CXCR3 & 1.16 & $5.66 \times 10^{-18}$ \\
\hline MYL5 & 1.04 & $5.64 \times 10^{-17}$ \\
\hline ADAT2 & 1.14 & $2.06 \times 10^{-16}$ \\
\hline RBM3 & 1.91 & $7.68 \times 10^{-16}$ \\
\hline HKDC1 & 1.03 & $1.99 \times 10^{-15}$ \\
\hline TARBP1 & 1.17 & $3.04 \times 10^{-15}$ \\
\hline LOC791120 & 1.15 & $4.04 \times 10^{-15}$ \\
\hline $\mathrm{IGH}$ & 1.19 & $2.94 \times 10^{-14}$ \\
\hline TK1 & 1.04 & $5.89 \times 10^{-14}$ \\
\hline SPTA1 & 1.09 & $3.88 \times 10^{-6}$ \\
\hline RNF182 & 1.42 & $6.73 \times 10^{-7}$ \\
\hline ANXA3 & -2.60 & $4.80 \times 10^{-24}$ \\
\hline UPP1 & -1.75 & $2.85 \times 10^{-23}$ \\
\hline RAB24 & -1.10 & $3.35 \times 10^{-23}$ \\
\hline CD177 & -2.52 & $3.60 \times 10^{-23}$ \\
\hline CARD17 & -1.99 & $1.40 \times 10^{-22}$ \\
\hline S100A9 & -1.87 & $1.43 \times 10^{-22}$ \\
\hline FCGR1B & -2.46 & $2.45 \times 10^{-22}$ \\
\hline C19orf59 & -2.70 & $4.38 \times 10^{-22}$ \\
\hline S100A12 & -2.25 & $7.53 \times 10^{-22}$ \\
\hline LILRA5 & -1.55 & $1.31 \times 10^{-21}$ \\
\hline HSPA6 & -1.50 & $4.27 \times 10^{-20}$ \\
\hline CD59 & -1.42 & $4.92 \times 10^{-20}$ \\
\hline GALNT3 & -1.38 & $9.15 \times 10^{-19}$ \\
\hline TMEM49 & -1.04 & $4.52 \times 10^{-18}$ \\
\hline PPP1R3B & -1.43 & $7.36 \times 10^{-18}$ \\
\hline TIFA & -1.91 & $5.18 \times 10^{-17}$ \\
\hline TRIM25 & -1.19 & $5.94 \times 10^{-17}$ \\
\hline WDFY3 & -1.33 & $2.45 \times 10^{-16}$ \\
\hline KIF1B & -1.37 & $2.77 \times 10^{-16}$ \\
\hline CREB5 & -1.24 & $1.44 \times 10^{-15}$ \\
\hline PSTPIP2 & -1.48 & $2.53 \times 10^{-15}$ \\
\hline B4GALT5 & -1.24 & $3.15 \times 10^{-15}$ \\
\hline GAS7 & -1.29 & $4.45 \times 10^{-15}$ \\
\hline ACSL1 & -1.68 & $9.49 \times 10^{-15}$ \\
\hline KREMEN1 & -1.53 & $1.86 \times 10^{-14}$ \\
\hline IL8RA & -1.07 & $1.41 \times 10^{-13}$ \\
\hline CLEC2B & -1.49 & $1.71 \times 10^{-13}$ \\
\hline LRRK2 & -1.00 & $1.99 \times 10^{-13}$ \\
\hline CSTA & -1.30 & $6.85 \times 10^{-12}$ \\
\hline SCN9A & -1.04 & $1.36 \times 10^{-11}$ \\
\hline CEBPD & -1.26 & $8.96 \times 10^{-11}$ \\
\hline CLEC1A & -1.24 & $1.17 \times 10^{-7}$ \\
\hline NECAB1 & -1.05 & $6.29 \times 10^{-7}$ \\
\hline LRRN1 & -1.28 & $9.69 \times 10^{-7}$ \\
\hline LYVE1 & -1.31 & $1.02 \times 10^{-5}$ \\
\hline
\end{tabular}

These genes included top 10 differentially expressed genes and 28 differentially expressed genes that overlapped with target genes of differentially expressed microRNAs. DEGs, differentially expressed genes; KD, Kawasaki disease.
Functional enrichment analysis. The target genes of exosomal DE-miRNAs were subjected to analysis by DAVID for a functional enrichment analysis. The results indicated that 79 significant GO-biological process (BP) terms were enriched, including GO:0045893, positive regulation of transcription, DNA-templated (including CREB5); GO:0043406, positive regulation of MAP kinase activity (including LRRK2); and GO:0005975, carbohydrate metabolic process (including B4GALT5; Table III). A total of seven significant KEGG pathways were also enriched with target genes of exosomal DE-miRNAs, including hsa04390: Hippo signaling pathway (including WNT4, WNT8B); hsa05161: Hepatitis B (including CREB5); hsa04931: Insulin resistance (including CREB5 and PPP1R3B); and hsa04151: PI3K-Akt signaling pathway (including CREB5; Table IV).

The target genes of DE-miRNAs that overlapped with DEGs were also subjected to analysis by DAVID for functional prediction. Only one significant GO-BP term (GO:0060828, regulation of canonical Wnt signaling pathway, including LRRK2; Table III) and KEGG pathway (hsa00512: Mucin type O-Glycan biosynthesis, including B4GALT5; Table IV) were enriched.

\section{Discussion}

The present study demonstrated that exosomal miR-328, miR-575, miR-134 and miR-671-5p in serum may be used as biomarkers for the diagnosis of KD and for the prediction of therapeutic outcomes of the IVIG therapy. miR-328 was upregulated, and miR-575, miR-134 and miR-671-5p were downregulated in patients with KD. These trends were reversed following IVIG treatment, leading to downregulation of miR-328, and upregulation of miR-575, miR-134 and miR-671-5p. The present study identified novel exosomal miRNAs (miR-575 and miR-134), in addition to those reported in the study by Jia et al (27) (miR-328 and miR-671-5p).

There have been a few studies that have investigated the miRNAs in KD prior to and following IVIG therapy $(22,40,41)$. However, the roles of miR-328, miR-575, miR-134 and miR-671-5p remain unclear. Previous studies have suggested that some of these miRNAs are predictors for coronary artery diseases $(42,43)$. He et al (42) demonstrated that elevated plasma miR-328 levels could distinguish between patients with acute myocardial infarction (AMI) and the control group, with an AUC of 0.887. Wang et al (43) also reported good diagnostic performance of miR-328 in plasma $(\mathrm{AUC}=0.810)$ and in whole blood (AUC=0.872) for patients with AMI. These results suggested that the miRNAs selected in the present study may identify the presence of cardiovascular lesions in KD. Although previous evidence indicated that miR-134 may serve a diagnostic role in AMI, this result was not consistent with the results of the present study (miR-134 was previously upregulated in AMI, but was downregulated in the present study) $(42,44)$. This difference may be attributed to the difference in the miRNA spectrum between the plasma and serum (45), or between the whole serum and the exosomal fraction. Therefore, further clinical studies are needed to confirm the diagnostic value of the exosomal miRNAs identified in the present study. 
Table III. GO enrichment analysis for target genes of DE-miRNAs in exosomes of serum from healthy children, patients with $\mathrm{KD}$ and patients with KD patients following IVIG therapy.

A, Target genes of DE-miRNAs

\begin{tabular}{lll}
\hline Term & P-value Genes
\end{tabular}

GO:0045893, positive regulation of transcription, DNA-templated

GO:0045944, positive regulation of transcription from RNA polymerase II promoter

GO:0043200, response to amino acid GO:0043406, positive regulation of MAP kinase activity GO:0043268, positive regulation of potassium ion transport GO:0051091, positive regulation of sequence-specific DNA binding transcription factor activity

GO:0019228, neuronal action potential GO:0014066, regulation of

phosphatidylinositol 3-kinase signaling GO:0050890, cognition

GO:0007265, Ras protein signal transduction

GO:0014070, response to organic cyclic compound

GO:0047496, vesicle transport along microtubule

GO:0010842, retina layer formation

GO:0061024, membrane organization GO:0008585, female gonad development GO:0060021, palate development

GO:0090073, positive regulation of protein homodimerization activity GO:0048565, digestive tract development GO:0007059, chromosome segregation

GO:0042552, myelination GO:0001764, neuron migration 1.39x10 ${ }^{-5}$ PPARD, GDF2, MITF, ZXDC, TGFB3, NFKB1, CTCF, GLI3, LGR4, ZIC3, WNT4, RRN3, ZNF281, TBL1XR1, EGR2, FOXJ2, SOX11, MED14, RB1, ESR2, MED13, SIX4, HIPK2, MAPK3, ZNF711, TFAP2B, ERBB4, HOXA11, SOX2, EHF, CDH1, NFYA, TFAM, NR1D2, NPAT, CREBL2, KLF6, IL5, TRIP4, TBX3, SMAD4, IGF1, MSTN, CREB5, ATMIN, FZD4, RLF, YWHAH, SFRP1, SP1, SETD7, NEUROD1, TP53INP2, F2R

$1.05 \times 10^{-3}$ CCNT2, HLF, GDF2, RNASEL, E2F8, STAT5B, MITF, EDN1, ARID4B,TGFB3, CTCF, NFKB1, GLI3, ZIC3, ZBTB38, CRX, PGR, PCGF5, ZNF304, SERPINE1, OGT, FGF1, TBL1XR1, SATB2, EXOSC9, EGR2, FOXJ2, SOX11, MTA2, RXRA, MED14, RB1, SIX4, MED13, CD40, GRHL2, GTF2H1, ACVR2A, VEGFA, MAPK3, HIPK2, TFAP2B, TFAP2C, CRTC3, FGFR2, SOX2, ONECUT2, TAF9B, EHF, EGLN1, CDC73, NR2C2, ATF1, TFAM, CHD7, NIPBL, DDX3X, PKD2, MYF6, IKZF4, IKZF1, CEBPD, SMAD4, IGF1, EN2, CSRP3, TET1, PARK7, DDX58, RLF, ATRX, SP1, TRPS1, NEUROD1, IRF2, NHLH2, PBX3, PBX2, FOXI1

1.36 $\times 10^{-3}$ ICAM1, SLC1A2, GLRB, MTHFR, CDKN1B, GLRA3, EDN1, CDO1

$1.49 \times 10^{-3}$ RASGRP1, EDN1, VEGFA, PDE5A, ADRA2A, KITLG, PDGFC, KIT, CD40, FGF1, LRRK2

$1.57 \times 10^{-3}$ DRD1, KIF5B, ADRA2A, STK39, DLG1

2.15×10-3 IL5, EDN1, TRIM27, TRIM14, TRIM25, ESR2, KIT, FZD4, TRIM21, PARK7, DDX58, TRIM32, HIPK2, NEUROD1, NHLH2

3.97x10-3 DRD1, SCN1A, SCN3A, GRIK2, ANK3, KCNA1, SCN9A

4.01 x10-3 FGFR2, C3ORF58, EREG, ERBB4, ERBB3, RASGRP1, MAPK3, KITLG, KIT, FGF1, PIP4K2A, PIP4K2C

5.41 $\times 10^{-3}$ MAGT1, CHD7, NIPBL, PTCHD1, NF1, CHRNA4, CHRNB2, CHMP2B

5.42×10-3 ZNF304, PLD1, PLCE1, RASGRP1, NF1, ADRA2A, IGF1, RB1, SHC3, KSR1, PARK7

5.50x10-3 ICAM1, CD83, ACSL1, SFRP1, TRPA1, ABCC4, ABCD3, COMT, ATF1

6.24x10-3 DYNC1I1, NDEL1, KIF5B, HTT, RASGRP1

$6.48 \times 10^{-3}$ PROM1, HIPK2, FJX1, TFAP2B, CALB1, DSCAM

$7.89 \times 10^{-3}$ YWHAH, RAB14, YWHAB, TBC1D4, PMP2, RAB10, YWHAE

$8.14 \times 10^{-3}$ WNT4, COL9A3, SFRP1, ZFP42, TIPARP

9.66 $\times 10^{-3}$ WFIKKN2, ACVR2B, SATB2, CHD7, TBX3, TIPARP, TGFB3, SMAD4, COL2A1, C5ORF42, GLI3

$1.14 \times 10^{-2}$ CRBN, TIRAP, PARK7, TRAF4

$1.22 \times 10^{-2}$ FGFR2, TRPS1, TGFB3, PDGFC, RB1, KIT, LGR4

1.32 $\times 10^{-2}$ CIAO1, NDEL1, DDX3X, PPP1R7, SLC25A5, USP9X, NEK9, CTCF, SRPK1, MIS12

$1.34 \times 10^{-2}$ EGR2, TSPAN2, MAL2, ATRN, CMTM8, XK, QKI, ACSBG1

$1.44 \times 10^{-2}$ SATB2, TUBB2B, USP9X, CELSR1, PCM1, YWHAE, SEMA6A, NDEL1, NAV1, CCR4, NEUROD4, DCX, MYH10 
Table III. Continued.

A, Target genes of DE-miRNAs

\begin{tabular}{|c|c|c|}
\hline Term & P-value & Genes \\
\hline $\begin{array}{l}\text { GO:0043154, negative regulation of } \\
\text { cysteine-type endopeptidase activity } \\
\text { involved in apoptotic process }\end{array}$ & $1.45 \times 10^{-2}$ & $\begin{array}{l}\text { ARL6IP1, LAMP3, DDX3X, TNFAIP8, VEGFA, TFAP2B, USP47, } \\
\text { RAG1, BIRC5, YWHAE }\end{array}$ \\
\hline GO:0035136, forelimb morphogenesis & $1.56 \times 10^{-2}$ & NIPBL, TBX3, RNF165, TFAP2B \\
\hline $\begin{array}{l}\text { GO:0007156, homophilic cell adhesion } \\
\text { via plasma membrane adhesion } \\
\text { molecules }\end{array}$ & $1.59 \times 10^{-2}$ & $\begin{array}{l}\text { PCDHA6, ME2, PCDHA2, CLSTN2, CADM2, PCDH9, CDH1, PTPRT, } \\
\text { CELSR1, CDH2, IGSF9B, PCDHAC2, PCDHAC1, CDH9, PCDHA10, } \\
\text { ROBO2, DSCAM }\end{array}$ \\
\hline GO:0043372, positive regulation of & $1.74 \times 10^{-2}$ & CD83, TNFSF4, SASH3 \\
\hline
\end{tabular}

CD4-positive, alpha-beta $\mathrm{T}$ cell

differentiation

GO:0010951, negative regulation of

endopeptidase activity

GO:0005975, carbohydrate metabolic

process

GO:0040007, growth

GO:0006513, protein monoubiquitination

GO:0001894, tissue homeostasis

GO:0048745, smooth muscle tissue

development

GO:0046622, positive regulation of

organ growth

GO:0061045, negative regulation of

wound healing

GO:0007519, skeletal muscle tissue

development

GO:0048839, inner ear development

GO:0031954, positive regulation of

protein autophosphorylation

GO:0097150, neuronal stem cell

population maintenance

GO:0033157, regulation of intracellular

protein transport

GO:0021631, optic nerve morphogenesis

GO:0048511, rhythmic process

GO:0070911, global genome

nucleotide-excision repair

GO:0098609, cell-cell adhesion

$1.80 \times 10^{-2}$ WFIKKN2, C5, CD109, PAPLN, FURIN, A2ML1, WFDC8, SERPINE2, SERPINE1, TFPI, PEBP1, ITIH5, CSTA, CRIM1

$1.83 \times 10^{-2}$ GALNT3, GANAB, FUT9, GNPDA2, ST8SIA1, GPD1L, MAN2A2, PGM2, PGM3, GANC, ALDH1B1, SLC2A2, AKR1B1, ST8SIA5, FUT4, SPAM1, B4GALT5, PYGB

$1.83 \times 10^{-2}$ OPA3, BMP3, GDF2, VEGFA, BMP8B, FOXP2

$1.83 \times 10^{-2}$ TSG101, DTL, KLHL12, RAD18, TRIM25, TRIM21

$1.93 \times 10^{-2}$ AKR1B1, TRIM32, COL2A1, RB1, TP53INP2

$2.06 \times 10^{-2}$ NF1, TIPARP, DLG1, FOXP2

$2.06 \times 10^{-2}$ ARX, IL7, RAG2, SASH3

2.06 $\times 10^{-2}$ WNT4, HMGCR, SERPINE1, CD109

2.28×10-2 MYF6, CCNT2, CFL2, NF1, SIX4, FLNB, CSRP3, FOXP2

2.56x $10^{-2}$ CDKN1B, CXCL14, CEBPD, DUOX2, SOX2, TGFB3, NEUROD1

$2.73 \times 10^{-2}$ RAP2B, VEGFA, PDGFC, RAD50, CALM2

$2.73 \times 10^{-2}$ SOX2, CDH2, PCM1, HOOK3, MMP24

$2.80 \times 10^{-2}$ NDEL1, SH3TC2, LCP1

$2.80 \times 10^{-2}$ CHRNB2, GLI3, EPHB 1

$3.03 \times 10^{-2}$ HLF, SP1, NR1D2, SFPQ, PASD1, PRKAA2, NFYA, FBXL3

$3.13 \times 10^{-2}$ SUMO3, UBE2N, DDB2, ERCC4, USP45, GTF2H1

$3.13 \times 10^{-2}$ ZC3HAV1, KIF5B, CKAP5, RPL15, YWHAB, TRIM25, ARFIP1, FLNB, YWHAE, PARK7, MMP24, CHMP2B, EIF4G2, GAPVD1, DDX3X, FNBP1L, SERBP1, TMOD3, PCMT1, DNAJB1, MAPRE1, RAB10, UBAP2, AHNAK

GO:0039702, viral budding via host

3.20x10-2 CHMP1A, TSG101, CHMP6, VPS37C, CHMP2B

ESCRT complex

GO:0060078, regulation of postsynaptic membrane potential GO:0006366, transcription from RNA polymerase II promoter

$3.20 \times 10^{-2}$ SCN1A, SCN3A, PKD2, SCN9A, SCN4B

$3.28 \times 10^{-2}$ CCNT2, NCBP2, HLF, POLR2E, STAT5B, TAF9B, MITF, SOX2, ONECUT2, NFKB1, EHF, CTCF, NFYA, GLI3, ATF1, ZIC3, CRX, TFAM, MAX, DDX21, VEZF1, MYF6, ZNF831, EGR2, FOXJ2, CEBPD, SOX11, SNAPC3, SMAD4, CREB5, SIX4, GRHL2, GTF2H1, TRPS1, TFAP2B, IRF2, NEUROD1, TFAP2C, PBX3, FOXI1 
Table III. Continued.

A, Target genes of DE-miRNAs

\begin{tabular}{l} 
Term \\
\hline GO:0006044, N-acetylglucosamine \\
metabolic process \\
GO:0060134, prepulse inhibition \\
GO:0032897, negative regulation \\
of viral transcription \\
GO:0007399, nervous system \\
development
\end{tabular}

GO:0045892, negative regulation of transcription, DNA-templated

GO:0015758, glucose transport GO:0051402, neuron apoptotic process GO:0006914, autophagy

GO:0050680, negative regulation of epithelial cell proliferation GO:0006479, protein methylation GO:0045662, negative regulation of myoblast differentiation

GO:0046854, phosphatidylinositol phosphorylation GO:0045787, positive regulation of cell cycle GO:0007585, respiratory gaseous exchange GO:0006813, potassium ion transport

GO:0051260, protein homooligomerization

GO:0034454, microtubule anchoring at centrosome GO:0035020, regulation of Rac protein signal transduction GO:0010606, positive regulation of cytoplasmic mRNA processing body assembly GO:0010960, magnesium ion homeostasis GO:0071910, determination of liver left/right asymmetry

GO:0045165, cell fate commitment GO:0071456, cellular response to hypoxia

GO:0032456, endocytic recycling GO:0030307, positive regulation of cell growth

P-value Genes

$3.29 \times 10^{-2}$ CHST7, GNPDA2, GNPNAT1, MGEA5

$3.29 \times 10^{-2}$ DRD1, SLC6A3, NRXN1, CTNNA2

$3.29 \times 10^{-2}$ TRIM32, TRIM14, TRIM27, TRIM21

3.30×10-2 PCDHA6, GLRB, FUT9, MOBP, PCDHA2, ERBB4, CAMK2G, ARID1B, IGSF9B, GAS7, NR2C2, PCDHAC2, PCDHAC1, SEMA6A, ATXN3, NDEL1, TPP1, VEGFA, MSI1, PCDHA10, DCX, CRIM1, DLG1, WNT8B, DSCAM

3.46×10-2 PPARD, GCLC, TSG101, CTCF, GLI3, LGR4, ZBTB38, WNT4, ZNF227, NIPBL, NR1D2, GATAD2A, ZNF425, PASD1, CRY1, BAHD1, MYF6, ZNF281, IKZF4, TNFSF4, TBX3, IKZF1, CEBPD, YWHAB, SMAD4, BIRC5, RB1, SIX4, FOXP2, CHMP1A, CDKN1B, SFRP1, TRIM33, EREG, SFPQ, RBAK, USP47, TFAP2B, XCL1

$3.52 \times 10^{-2}$ PPARD, SLC2A10, SLC2A2, EDN1, SLC2A1, HK2

$3.52 \times 10^{-2}$ MAX, USP53, GRIK2, ERBB3, RB1, NLRP1

$3.58 \times 10^{-2}$ TSG101, CHMP6, VPS41, VPS37C, PARK7, VTI1A, CHMP2B, TBC1D25, ATG5, FNBP1L, RB1CC1, ATG4A, LRRK2, VPS39

3.60×10-2 FGFR2, PPARD, EREG, SFRP1, SOX2, CDC73, RB1, DLG1

$3.70 \times 10^{-2}$ PCMTD2, BHMT, PCMT1, ETF1, N6AMT1

$3.70 \times 10^{-2}$ PPARD, TBX3, CXCL14, MSTN, CSRP3

3.75 $\times 10^{-2}$ FGFR2, EREG, ERBB4, ERBB3, PI4K2A, KITLG, PI4K2B, KIT, FGF1, PIP4K2A, PIP4K2C

$3.94 \times 10^{-2}$ FGFR2, ANKRD17, CDKN1B, TBX3, TRIM32, TRIM21

$3.94 \times 10^{-2}$ HNMT, TMPRSS11D, EDN1, CHRNA4, PBX3, TRAF4

$3.96 \times 10^{-2}$ KCNS3, KCNMA1, KCNS1, CDKN1B, SLC12A2, ATP4B, SLC24A3, KCNA1, KCNA6, KCNJ12

4.03 $\times 10^{-2}$ CCDC88C, GLRA3, KCNA1, PRND, KCNA6, KCNA7, KCNS3, ANXA6, STOM, KCNS1, CLDN1, KCTD16, ZBTB1, SLC1A1, EHD3, SPAST, KCTD12

$4.05 \times 10^{-2}$ KIF3A, PCM1, HOOK3

$4.05 \times 10^{-2}$ SSX2IP, OGT, CRK

$4.05 \times 10^{-2}$ CNOT6L, CNOT2, CNOT6

$4.05 \times 10^{-2}$ ANK3, KCNA1, TFAP2B

$4.05 \times 10^{-2}$ PKD2, CCDC39, ZIC3

4.22 $\times 10^{-2}$ FGFR2, WNT4, ERBB4, TRPS1, ONECUT2, NEUROD4, WNT8B

$4.24 \times 10^{-2}$ ICAM1, PPARD, PTGIS, TBL2, STC2, CPEB2, SFRP1, EDN1, VEGFA, BNIP3L, HIPK2

$4.25 \times 10^{-2}$ STX6, VPS52, RAB14, ARL4C, EHD3

4.52 $\times 10^{-2}$ EIF4G2, EXTL3, EXOSC9, DDX3X, SFRP1, TRIM32, TAF9B, USP47, H3F3B, N6AMT1 
Table III. Continued.

A, Target genes of DE-miRNAs

\begin{tabular}{lll}
\hline Term & P-value & Genes
\end{tabular}

GO:0042384, cilium assembly

GO:0009636, response to toxic substance

GO:2000679, positive regulation of transcription regulatory region DNA binding GO:0022408, negative regulation of cell-cell adhesion GO:0007076, mitotic chromosome condensation GO:0006351, transcription, DNA-templated

GO:0048661, positive regulation of smooth muscle cell proliferation GO:0045669, positive regulation of osteoblast differentiation GO:0000122, negative regulation of transcription from RNA polymerase II promoter 4.54x10-2 KIF3A, DZIP1, ONECUT2, PCM1, C5ORF42, ACTR2, TTC30A, FNBP1L, C10ORF90, ABCC4, SSX2IP, EXOC5, EHD3

4.81 $\times 10^{-2}$ GLYAT, MAPK3, SLC30A4, SLC6A14, SCN9A, CDH1, GUCY2C, HTR1D, NQO1, PON3

$4.82 \times 10^{-2}$ NEUROD1, IGF1, RB1, PARK7

$4.82 \times 10^{-2} \quad \mathrm{NF} 2, \mathrm{TNR}, \mathrm{EPB} 41 \mathrm{~L} 5, \mathrm{CDH} 1$

$4.82 \times 10^{-2}$ CHMP1A, NCAPH, NCAPG, CDCA5

4.96x10-2 IL16, ZNF451, ZXDC, CNOT2, ZNF250, MED22, CNOT6, ZNF254, PGR, ZNF304, EPC2, MIER3, ZNF445, CRY1, SAMD4B, ZNF449, IKBKAP, SATB2, RXRA, ARID1B, TRIM33, MAPK3, TGIF2, VGLL3, CRTC3, ERBB4, HOXA11, NR2C2, ARX, ZNF227, DDX3X, CNOT6L, ZNF697, ZNF425, ZNF124, CREBL2, IKZF4, KLF6, TRIP4, IKZF1, RFX5, SMAD4, ZNF521, ZNF320, ZNF585A, ZNF627, CSRP3, TET1, FOXP2, ZNF419, ZNF417, PNRC1, JAZF1, ZNF318, PHF6, CCNT2, PPARD, ZNF518B, ZNF81, ARID4B, ZFP42, E2F8, ZNF10, ZBTB38, PCGF5, HIF1AN, BRD9, ZNF281, NFKBIZ, TBL1XR1, ZNF33A, EGR2, ZNF354A, ZNF354C, ZFY, ZFX, SF1, RB1, ESR2, ZBTB26, PURB, GTF2H1, CHMP1A, BRWD1, HIPK2, ZNF711, ZNF480, LIN54, ZNF740, POLR2E, LIN9, SCML2, ZNF660, CHD7, ZSCAN22, NR1D2, RB1CC1, NPAT, GATAD2A, PRKAA2, ZNF470, BAHD1, ZNF267, TBX3, PPHLN1, CEBPD, NLK, ZNF770, ZFP1, ZNF667, TRIM27, BIRC5, ATMIN, ZNF665, RLF, ATRX, ATXN3, SFPQ, RBAK, ZBTB5, NHLH2, ZNF461, SETD7, NEUROD4, PBX2, ZNF766, TP53INP2

4.96 $\times 10^{-2}$ FGFR2, EREG, HMGCR, EDN1,AKR1B1, IGF1, ABCC4, CALCRL

4.96x10-2 ACVR2A, WNT4, ACVR2B, GDF2, CEBPD, SOX11, IGF1, GLI3

4.99×10 ${ }^{-2}$ PPARD, IMPACT, E2F8, EDN1, MITF, CNOT2, NFKB1, CTCF, HSBP1, ZNF254, GLI3, CRY1, DLG1, ZNF281, TBL1XR1, SATB2, SOX11, MTA2, RXRA, HNRNPA2B1, RB1, ESR2, PURB, ACVR2B, TRIM33, VEGFA, HIPK2, TFAP2B, TGIF2, TFAP2C, FGFR2, USP9X, TAF9B, SOX2, CDC73, ARX, NIPBL, GATAD2A, IKZF1, TBX3, RFX5, PTPN2, SMAD4, TRIM27, FOXP2, DLX1, DKK1, SFPQ, TRPS1, JAZF1, IRF2, ZBTB1

B, DEGs regulated by DE-miRNAs

\begin{tabular}{lcc}
\hline Term & P-value & Genes \\
\hline $\begin{array}{l}\text { GO:0060828, regulation of canonical } \\
\text { Wnt signaling pathway }\end{array}$ & $2.82 \times 10^{-2}$ & KREMEN1, LRRK2 \\
\hline $\begin{array}{l}\text { DE-miRNAs, differentially expressed miRNAs; miRNA, microRNA; GO, Gene Ontology; KD, Kawasaki disease; IVIG, intravenous immu- } \\
\text { noglobulin; DEGs, differentially expressed genes. }\end{array}$
\end{tabular}


Table IV. KEGG pathway enrichment analysis for target genes of differentially expressed miRNAs in exosomes of serum from healthy children, patients with KD and patients with KD following IVIG therapy.

A, Target genes of differentially expressed miRNAs

\begin{tabular}{|c|c|c|}
\hline Term & P-value & Genes \\
\hline hsa04390: Hippo signaling pathway & $6.54 \times 10^{-4}$ & $\begin{array}{l}\text { NF2, SOX2, YWHAB, TGFB3, SMAD4, TEAD1, CDH1, BIRC5, } \\
\text { YWHAE, FZD4, CTNNA2, WNT4, YWHAH, RASSF6, CCND3, } \\
\text { SERPINE1, AXIN2, FGF1, BMP8B, WNT8B, DLG1 }\end{array}$ \\
\hline hsa05200: Pathways in cancer & $2.19 \times 10^{-3}$ & $\begin{array}{l}\text { FGFR2, ADCY1, PPARD, STAT5B, MITF, TGFB3, KITLG, NFKB1, } \\
\text { EGLN1, CDH1, KIT, GLI3, CUL2, MAX, WNT4, RASGRP1, SLC2A1, } \\
\text { GNG2, AXIN2, FGF1, TRAF4, WNT8B, COL4A4, PTGER3, RXRA, } \\
\text { SMAD4, IGF1, BIRC5, RB1, FZD4, CTNNA2, CCDC6, LAMA4, } \\
\text { CDKN1B, MAPK3, VEGFA, LAMC2, CRK, F2R }\end{array}$ \\
\hline hsa05161: Hepatitis B & $2.70 \times 10^{-2}$ & $\begin{array}{l}\text { EGR2, STAT5B, YWHAB, TGFB3, TIRAP, SMAD4, BIRC5, CREB5, } \\
\text { NFKB1, RB1, DDX58, CDKN1B, DDX3X, MAPK3, TICAM2, DDB2 }\end{array}$ \\
\hline hsa04931: Insulin resistance & $2.79 \times 10^{-2}$ & $\begin{array}{l}\text { PRKAB2, CREB5, NFKB1, PRKCQ, PPP1R3B, SLC2A2, SLC2A1, } \\
\text { MGEA5, TBC1D4, GYS2, OGT, PRKAA2, PYGB }\end{array}$ \\
\hline hsa04066: HIF-1 signaling pathway & $3.23 \times 10^{-2}$ & $\begin{array}{l}\text { CUL2, CDKN1B, CAMK2G, MAPK3, EDN1, VEGFA, SLC2A1, } \\
\text { SERPINE1, HK2, IGF1, NFKB1, EGLN1 }\end{array}$ \\
\hline hsa04151: PI3K-Akt signaling pathway & $4.10 \times 10^{-2}$ & $\begin{array}{l}\text { FGFR2, PPP2R5A, KITLG, NFKB1, COL2A1, KIT, COL6A6, TNR, } \\
\text { GYS2, PDGFC, GNG2, PRKAA2, FGF1, THBS2, COL4A4, SGK2, } \\
\text { IL7, RXRA, YWHAB, IGF1, CREB5, YWHAE, LAMA4, CDKN1B, } \\
\text { YWHAH, CCND3, VEGFA, MAPK3, LAMC2, F2R }\end{array}$ \\
\hline hsa00500: Starch and sucrose metabolism & $4.51 \times 10^{-2}$ & PGM2, GANC, HK2, GYS2, PYGB, PGM2L1 \\
\hline
\end{tabular}

B, Differentially expressed genes regulated by differentially expressed miRNAs

Term P-value Genes

hsa00512: Mucin type O-Glycan

$2.82 \times 10^{-2}$ KREMEN1, LRRK2

biosynthesis

KEGG, Kyoto Encyclopedia of Genes and Genomes; GO, Gene Ontology; KD, Kawasaki disease; IVIG, intravenous immunoglobulin. 1, for all target genes of differentially expressed miRNAs; 2 , for differentially expressed genes regulated by differentially expressed miRNAs.

The present study also predicted that the selected miRNAs may be involved in KD by regulating the inflammatory target genes expressed in PBMCs. CXCR1 was one of the targets and previous studies have reported that IL-8 and its receptors, CXCR1 and $\mathrm{C}-\mathrm{X}-\mathrm{C}$ chemokine receptor type 2 , were upregulated in patients with KD (46) and in coronary artery diseases (47). By binding to CXCR1, IL-8 may promote the production of other inflammatory mediators through the activation of the $\mathrm{p} 38$-mitogen-activated protein kinase/extracellular signal-regulated kinase-nuclear factor (NF)-кB pathways (48), which may subsequently induce apoptosis in vascular endothelial cells, a potential mechanism for KD (49). In addition, transcription factor CREB was also reported to enhance inflammation by inducing IL-17A production and promoting coronary artery diseases, including atherosclerosis (50). B4GALT family genes encode enzymes for the biosynthesis of different glycoconjugates and saccharide structures and are involved in protein glycosylation (51). Lactosylceramide synthesized by B4GALT6 in astrocytes activated central nervous system (CNS)-infiltrating monocytes, in a non-cell-autonomous manner, by regulating granulocyte-macrophage colony-stimulating factor, resulting in chronic CNS inflammation (52). PPP1R3B is a gene encoding the hepatic glycogen-targeting subunit of protein phosphatase-1 (PP1), which targets PP1 to glycogen synthase, increasing the activity of this enzyme in the skeletal muscles and liver (53). It has been previously demonstrated that increased glycogen accumulation is associated with obesity-linked inflammation in humans (54). LRRK2 deficiency was reported to attenuate the lipopolysaccharide-induced expression of inducible nitric oxide synthase, TNF- $\alpha$, IL-1 $\beta$ and IL- 6 through inhibition of the p38 mitogen-activated protein kinase, and NF- $\mathrm{BB}$ pathways, and to alter neuroinflammation (55). ACSL1 enzyme catalyzes the thioesterification of fatty acids and is a marker of inflammatory activation. It has been reported that the inflammatory phenotype of diabetic mice is associated with the increased expression of ACSL1 (56). Myeloid-selective deletion of ACSL1 protects monocytes and macrophages from 
the inflammatory effects of diabetes and prevents accelerated atherosclerosis (56). Heterozygous loss of spectrin in mice lead to increased expression levels of IL- $1 \alpha$ and IL-1 $\beta$ through the activation of signal transducer and activator of transcription 3 (57). Accordingly, the present study hypothesized that miR-328 may exhibit pro-inflammatory effects through the downregulation of SPTA1, and miR-575, miR-134 and miR-671-5p may exhibit anti-inflammatory effects, leading to the upregulation of CREB5, IL8RA, PPP1R3B, ACSL1 and LRRK2 in KD.

There are certain limitations that should be acknowledged when interpreting the results of the present study. Firstly, the sample size for screening exosomal miRNAs for KD was not large, and an increased number of samples should be analyzed in future studies. Secondly, although several exosomal miRNAs have been suggested as potential biomarkers for the diagnosis of KD and the prediction of therapeutic outcomes for IVIG therapy, further confirmation in clinical samples is necessary. Thirdly, negative associations between miRNAs and their target genes were revealed in the present study, however, in vitro and in vivo experiments are necessary to validate these results. Fourthly, the exosomal mechanisms of these four miRNAs remain to be elucidated.

In conclusion, the present study preliminarily revealed that exosomal miR-328, miR-575, miR-134 and miR-671-5p may serve as biomarkers for the diagnosis of KD and the prediction of therapeutic outcomes for IVIG therapy by influencing the expression levels of inflammatory genes.

\section{Acknowledgments}

Not applicable.

\section{Funding}

No funding was received.

\section{Availability of data and materials}

The datasets generated and/or analyzed during the current study are available in the NCBI database repository (https://www.ncbi. nlm.nih.gov/geo/query/acc.cgi?acc=GSE60965; https://www. ncbi.nlm.nih.gov/geo/query/acc.cgi?acc=GSE73577).

\section{Authors' contributions}

XFZ and DJS participated in the design of this study. XFZ and GDX performed the bioinformatics analyses. XFZ, GDX and DJS contributed to the acquisition and interpretation of data. XFZ and DJS were involved in drafting and revising the manuscript. All authors read and approved the final manuscript.

\section{Ethical approval and consent to participate}

Not applicable.

\section{Patient consent for publication}

Not applicable.

\section{Competing interests}

The authors declare that they have no competing interests.

\section{References}

1. Makino N, Nakamura Y, Yashiro M, Ae R, Tsuboi S, Aoyaa Y, Kojo T, Uehara R, Kotani K and Yanagawa H: Descriptive epidemiology of Kawasaki disease in Japan, 2011-2012: From the results of the 22nd nationwide survey. J Epidemiol 25: 239-245, 2015.

2. Kim GB, Han JW, Park YW, Song MS, Hong YM, Cha SH, Kim DS and Park S: Epidemiologic features of Kawasaki disease in South Korea: Data from nationwide survey, 2009-2011. Pediatr Infect Dis J 33: 24-27, 2014

3. Lue HC, Chen LR, Lin MT, Chang LY, Wang JK, Lee CY and Wu MH: Epidemiological features of Kawasaki disease in Taiwan, 1976-2007: Results of five nationwide questionnaire hospital surveys. Pediatr Neonatol 55: 92-96, 2014.

4. Chen JJ, Ma XJ, Liu F, Yan WL, Huang MR, Huang M and Huang GY; Shanghai Kawasaki Disease Research Group: Epidemiologic features of Kawasaki disease in shanghai from 2008 through 2012. Pediatr Infect Dis J 35: 7-12, 2016.

5. Hartopo AB and Setianto BY: Coronary artery sequel of Kawasaki disease in adulthood, a concern for internists and cardiologists. Acta Med Indones 45: 69-75, 2013.

6. Nakamura Y, Aso E, Yashiro M, Tsuboi S, Kojo T, Aoyama Y, Kotani K, Uehara R and Yanagawa H: Mortality among Japanese with a history of Kawasaki disease: Results at the end of 2009. J Epidemiol 23: 429-434, 2013.

7. Fukazawa R, Kobayashi T, Mikami M, Saji T, Hamaoka K, Kato H, Suzuki H, Tsuda E, Ayusawa M, Miura M, et al: Nationwide survey of patients with giant coronary aneurysm secondary to Kawasaki disease 1999-2010 in Japan. Circ J 82: 239-246, 2017.

8. Shulman ST: Intravenous immunoglobulin for the treatment of Kawasaki disease. Pediatr Ann 46: e25-e28, 2017.

9. Yoshida M, Oana S, Masuda H, Ishiguro A, Kato H, Ito S, Kobayashi T and Abe J: Recurrence of fever after initial intravenous immunoglobulin treatment in children with Kawasaki disease. Clin Pediatr (Phila) 57: 189-192, 2018.

10. Rigante D, Valentini P, Rizzo D, Leo A, De Rosa G, Onesimo R, De Nisco A, Angelone DF, Compagnone A and Delogu AB: Responsiveness to intravenous immunoglobulins and occurrence of coronary artery abnormalities in a single-center cohort of Italian patients with Kawasaki syndrome. Rheumatol Int 30: 841-846, 2010.

11. Pinna GS, Kafetzis DA, Tselkas OI and Skevaki CL: Kawasaki disease: An overview. Curr Opin Infect Dis 21: 263-270, 2008.

12. Motoki N, Akazawa Y, Yamazaki S, Hachiya A, Motoki H, Matsuzaki S and Koike K: Prognostic significance of QT interval dispersion in the response to intravenous immunoglobulin therapy in Kawasaki disease. Circ J 81: 537-542, 2017.

13. Komatsu $\mathrm{H}$ and Tateno A: Failure to distinguish systemic-onset juvenile idiopathic arthritis from incomplete Kawasaki disease in an infant. J Paediatr Child Health 43: 707-709, 2007.

14. Capittini C, Emmi G, Mannarino S, Bossi G, Dellepiane RM, Salice P, Pietrogrande MC, Pasi A, De Silvestri A, Tinelli C and Martinetti M: An immune-molecular hypothesis supporting infectious aetiopathogenesis of Kawasaki disease in children. Eur J Immunol 48: 543-545, 2018.

15. Hara T, Nakashima Y, Sakai Y, Nishio H, Motomura Y and Yamasaki S: Kawasaki disease: A matter of innate immunity. Clin Exp Immunol 186: 134-143, 2016.

16. Sato $\mathrm{S}$, Kawashima H, Kashiwagi Y and Hoshika A: Inflammatory cytokines as predictors of resistance to intravenous immunoglobulin therapy in Kawasaki disease patients. Int J Rheum Dis 16: 168-172, 2013.

17. Korematsu S, Uchiyama S, Miyahara H, Nagakura T, Okazaki N, Kawano T, Kojo M and Izumi T: The characterization of cerebrospinal fluid and serum cytokines in patients with Kawasaki disease. Pediatr Infect Dis J 26: 750-753, 2007.

18. Rasouli M, Heidari B and Kalani M: Downregulation of Th17 cells and the related cytokines with treatment in Kawasaki disease. Immunol Lett 162: 269-275, 2014.

19. Engelberg R, Martin M, Wrotniak BH and Hicar MD: Observational study of Interleukin-21 (IL-21) does not distinguish Kawasaki disease from other causes of fever in children. Pediatr Rheumatol Online J 15: 32, 2017. 
20. Hu P, Jiang GM, Wu Y, Huang BY, Liu SY, Zhang DD, Xu Y, Wu YF, Xia X, Wei W and Hu B: TNF- $\alpha$ is superior to conventional inflammatory mediators in forecasting IVIG nonresponse and coronary arteritis in Chinese children with Kawasaki disease. Clin Chim Acta 471: 76-80, 2017.

21. Chen X, Ba Y, Ma L, Cai X, Yin Y, Wang K, Guo J, Zhang Y, Chen J, Guo X, et al: Characterization of microRNAs in serum: A novel class of biomarkers for diagnosis of cancer and other diseases. Cell Res 18: 997-1006, 2008.

22. Yun KW, Lee JY, Yun SW, Lim IS and Choi ES: Elevated serum level of microRNA (miRNA) -200c and miRNA-371-5p in children with Kawasaki disease. Pediatr Cardiol 35: 745-752, 2014.

23. Zhang W, Wang Y, Zeng Y, Hu L and Zou G: Serum miR-200c and miR-371-5p as the useful diagnostic biomarkers and therapeutic targets in Kawasaki disease. Biomed Res Int 2017: 8257862,2017

24. Wang S, Wang JQ and Lv XW: Exosomal miRNAs as biomarkers in the diagnosis of liver disease. Biomark Med 11: 491-501, 2017.

25. Matsumura T, Sugimachi K, Iinuma H, Takahashi Y, Kurashige J, Sawada G, Ueda M, Uchi R, Ueo H, Takano Y, et al: Exosomal microRNA in serum is a novel biomarker of recurrence in human colorectal cancer. Br J Cancer 113: 275-281, 2015.

26. Tanaka Y, Kamohara H, Kinoshita K, Kurashige J, Ishimoto T, Iwatsuki M, Watanabe $M$ and Baba H: Clinical impact of serum exosomal microRNA-21 as a clinical biomarker in human esophageal squamous cell carcinoma. Cancer 119: 1159-1167, 2013.

27. Jia HL, Liu CW, Zhang L, Xu WJ, Gao XJ, Bai J, Xu YF, Xu MG and Zhang G: Sets of serum exosomal microRNAs as candidate diagnostic biomarkers for Kawasaki disease. Sci Rep 7: 44706, 2017.

28. Higuchi T, Fukuda N, Yamamoto C, Yamazaki T, Oikawa O, Ohnishi Y, Okada K, Soma M and Matsumoto K: The influence of uremic serum on interleukin-1beta and interleukin-1 receptor antagonist production by peripheral blood mononuclear cells. Ther Apher Dial 10: 65-71,2006.

29. Clinchy B, Gunneras M, Hakansson A and Hakansson L: Production of IL-1Ra by human mononuclear blood cells in vitro: Influence of serum factors. Cytokine 34: 320-330, 2006.

30. Alidjinou EK, Sané F, Engelmann I and Hober D: Serum-dependent enhancement of coxsackievirus B4-induced production of IFN $\alpha$, IL- 6 and TNF $\alpha$ by peripheral blood mononuclear cells. J Mol Biol 425: 5020-5031, 2013

31. Sandri S, Hatanaka E, Franco AG, Pedrosa AM, Monteiro HP and Campa A: Serum amyloid A induces CCL20 secretion in mononuclear cells through MAPK (p38 and ERK1/2) signaling pathways. Immunol Lett 121: 22-26, 2008.

32. Harshyne LA, Nasca BJ, Kenyon LC, Andrews DW and Hooper DC: Serum exosomes and cytokines promote a T-helper cell type 2 environment in the peripheral blood of glioblastoma patients. Neuro Oncol 18: 206-215, 2016.

33. Zhou X, Jiao Z, Ji J, Li S, Huang X, Lu X, Zhao H, Peng J, Chen X, Ji Q and Ji Y: Characterization of mouse serum exosomal small RNA content: The origins and their roles in modulating inflammatory response. Oncotarget 8: 42712-42727, 2017.

34. Okuzaki D, Ota K, Takatsuki SI, Akiyoshi Y, Naoi K, Yabuta N, Saji T and Nojima H: FCN1 (M-ficolin), which directly associates with immunoglobulin G1, is a molecular target of intravenous immunoglobulin therapy for Kawasaki disease. Sci Rep 7: 11334, 2017.

35. Bolstad BM: Bolstad B preprocessCore: A collection of pre-processing functions. R Package version 1.28. 0, 2013.

36. Smyth GK: Limma: Linear models for microarray data. Bioinformatics and computational biology solutions using $\mathrm{R}$ and Bioconductor. Springer, pp397-420, 2005.

37. Kolde R: (2015) Pheatmap: Pretty Heatmaps. R package version 1.0. 8, 2015.

38. Kohl M, Wiese S and Warscheid B: Cytoscape: software for visualization and analysis of biological networks. Methods Mol Biol 696: 291-303, 2011.

39. Huang DW, Sherman BT and Lempicki RA: Systematic and integrative analysis of large gene lists using DAVID bioinformatics resources. Nat Protoc 4: 44-57, 2009.

40. Rong X, Jia L, Hong L, Pan L, Xue X, Zhang C, Lu J, Jin Z, Qiu H, Wu R and Chu M: Serum miR-92a-3p as a new potential biomarker for diagnosis of Kawasaki disease with coronary artery lesions. J Cardiovasc Transl Res 10: 1-8, 2017.
41. Shimizu C, Kim J, Stepanowsky P, Trinh C, Lau HD, Akers JC, Chen C, Kanegaye JT, Tremoulet A, Ohno-Machado L and Burns JC: Differential Expression of miR-145 in Children with Kawasaki disease. PLoS One 8: e58159, 2013

42. He F, Lv P, Zhao X, Wang X, Ma X, Meng W, Meng X and Dong S: Predictive value of circulating miR-328 and miR-134 for acute myocardial infarction. Mol Cell Biochem 394: 137-144, 2014.

43. Wang R, Li N, Zhang Y, Ran Y and Pu J: Circulating microRNAs are promising novel biomarkers of acute myocardial infarction. Intern Med 50: 1789-1795, 2011.

44. Wang KJ, Zhao X, Liu YZ, Zeng QT, Mao XB, Li SN, Zhang M, Jiang C, Zhou Y, Qian C, et al: Circulating MiR-19b-3p, MiR-134-5p and MiR-186-5p are promising novel biomarkers for early diagnosis of acute myocardial infarction. Cell Physiol Biochem 38: 1015-1029, 2016.

45. Wang K, Yuan Y, Cho JH, Mcclarty S, Baxter D and Galas DJ: Comparing the MicroRNA spectrum between serum and plasma. PLoS One 7: e41561, 2012.

46. Jiang J, Cai Y, Li Z, Huang L, Chen J, Tian L, Wu Z, Li X, Chen Z, Chen $\mathrm{C}$ and Yang Z: Screening of differentially expressed genes associated with Kawasaki disease by microarray analysis. Exp Ther Med 14: 3159-3164, 2017.

47. Leonard DA, Merhige ME, Williams BA and Greene RS: Elevated expression of the interleukin- 8 receptors CXCR1 and CXCR 2 in peripheral blood cells in obstructive coronary artery disease. Coron Artery Dis 22: 491-496, 2011.

48. Chan LP, Liu C, Chiang FY, Wang LF, Lee KW, Chen WT, Kuo PL and Liang CH: IL-8 promotes inflammatory mediators and stimulates activation of $\mathrm{p} 38 \mathrm{MAPK} / \mathrm{ERK}-\mathrm{NF}-\kappa \mathrm{B}$ pathway and reduction of JNK in HNSCC. Oncotarget 8: 56375-56388, 2017.

49. Li Z, Jiang J, Tian L, Li X, Chen J, Li S, Li C and Yang Z: A plasma mir-125a-5p as a novel biomarker for Kawasaki disease and induces apoptosis in HUVECs. PLoS One 12: e0175407, 2017.

50. Kotla S, Singh NK, Heckle MR, Tigyi GJ and Rao GN: The transcription factor CREB enhances interleukin-17A production and inflammation in a mouse model of atherosclerosis. Sci Signal 6: ra83, 2013.

51. Zhou H, Ma H, Wei W, Ji D, Song X, Sun J, Zhang J and Jia L: B4GALT family mediates the multidrug resistance of human leukemia cells by regulating the hedgehog pathway and the expression of p-glycoprotein and multidrug resistance-associated protein 1. Cell Death Dis 4: e654, 2013.

52. Mayo L, Trauger SA, Blain M, Nadeau M, Patel B, Alvarez JI, Mascanfroni ID, Yeste A, Kivisäkk P, Kallas K, et al: Regulation of astrocyte activation by glycolipids drives chronic CNS inflammation. Nat Med 20: 1147-1156, 2014

53. Mehta MB, Shewale SV, Sequeira RN, Millar JS, Hand NJ and Rader DJ: Hepatic protein phosphatase 1 regulatory subunit 3B (Ppp1r3b) promotes hepatic glycogen synthesis and thereby regulates fasting energy homeostasis. J Biol Chem 292: 10444-10454, 2017.

54. Ceperuelo-Mallafré V, Ejarque M, Serena C, Duran X, Montori-Grau M, Rodríguez MA, Yanes O, Núñez-Roa C, Roche K, Puthanveetil P, et al: Adipose tissue glycogen accumulation is associated with obesity-linked inflammation in humans. Mol Metab 5: 5-18, 2015.

55. Kim B, Yang MS, Choi D, Kim JH, Kim HS, Seol W, Choi S, Jou I, Kim EY and Joe EH: Impaired inflammatory responses in murine Lrrk2-knockdown brain microglia. PLoS One 7: e34693, 2012.

56. Kanter JE, Kramer F, Barnhart S, Averill MM, Vivekanandan-Giri A, Vickery T, Li LO, Becker L, Yuan W, Chait A, et al: Diabetes promotes an inflammatory macrophage phenotype and atherosclerosis through acyl-CoA synthetase 1. Proc Natl Acad Sci USA 109: E715-E724, 2012.

57. Lin L, Wang H, Gao B, Zhi X and He AR: Abstract 5184: Mechanistic analysis of liver inflammation and cancer formation in mice with heterozygous lose of $\beta$-spectrin $(\beta 2 \mathrm{SP})$. Cancer Res 73: 5184-5184, 2013.

This work is licensed under a Creative Commons Attribution-NonCommercial-NoDerivatives 4.0 International (CC BY-NC-ND 4.0) License. 